Article

\title{
The Effects of Team-Game-Tournaments Application towards Learning Motivation and Motor Skills in College Physical Education
}

\author{
Yu-Jy Luo ${ }^{1}$, Mei-Ling Lin ${ }^{2}$, Chien-Huei Hsu ${ }^{3}$, Chun-Chin Liao ${ }^{1}$ and Chun-Chieh Kao ${ }^{1, *(1)}$ \\ 1 Office of Physical Education, Ming Chuan University, Taoyuan 333, Taiwan; \\ anitaluo@mail.mcu.edu.tw (Y.-J.L.); luck@mail.mcu.edu.tw (C.-C.L.) \\ 2 Office of Physical Education, Mackay Junior College of Medicine, Nursing \& Management, Taipei 112, \\ Taiwan; s091@mail.mkc.edu.tw \\ 3 Early Childhood Care and Education, University of Kang-Ning, Taipei 114, Taiwan; chienhuei@ukn.edu.tw \\ * Correspondence: kao@mail.mcu.edu.tw; Tel.: +886-3-3507-001
}

Received: 21 June 2020; Accepted: 22 July 2020; Published: 30 July 2020

check for updates

\begin{abstract}
Physical education (PE) helps form lifelong learning and exercise habits; therefore, PE courses should be designed to enhance student motivation. Team-game tournaments (TGTs) enable learning in heterogeneous groups and involve positive interdependence, individual accountability, social skills, face-to-face interaction, group processing, and equal opportunities. Therefore, this quasi-experimental pre-test-post-test study investigated the effects of the TGT on learning motivation and motor skills. In this study, 108 students who enrolled in an advanced basketball course from two classes in a Taiwanese university were recruited as participants. Experimental teaching was implemented based on the class patterns, during which the students were divided into experimental and control groups. The control group, consisting of 56 students ( 46 male and 10 female), received conventional PE. In the TGT experimental group, constituting 52 students ( 40 male and 12 female), the TGT learning program was implemented. After a 12-week basketball teaching session, the TGT teaching strategy significantly improved student motivation but not motor skill acquisition. Competency level, however, did not significantly affect motivation but was significantly related to motor skill acquisition. Interaction effects between teaching strategy and competency level were non-significant. Despite TGTs enhancing learning motivation, PE teachers are still responsible for teaching rules, knowledge, and skills, engaging team members, and ensuring sufficient time for skill practice.
\end{abstract}

Keywords: teaching strategy; learning effectiveness; cooperative learning; team sports

\section{Introduction}

\subsection{Research Background}

Physical education courses are a continuous program developed based on the appropriate development of all stages of education. The main objectives are not only offering physical training that makes students stronger and healthier, but also assisting students to acquire relevant knowledge, physical experience, interpersonal interaction, and teamwork through physical education, and these courses have a profound impact on students' physical exercise and lifelong exercise habits, especially their level of sports involvement after leaving university [1-5]. In contemporary society, cooperation between groups and within groups has become important in line with scientific and technological developments. People and societies need to develop the behavior to work in collaboration with other people and countries, particularly in education, to develop collaborative skills [6]. The Programme for International Student Assessment (PISA), which covers $87 \%$ of the 
world, has listed collaborative problem solving as a formal evaluation since 2015 [7], indicating a foreseeable future where cooperative learning is emphasized. Various new teaching trends have taken off in the education field in recent years, including learning communities, flipped classrooms, and mobile learning, demonstrating that conventional didactic teaching and independent learning have gradually been replaced by novel teaching methods, and that cooperative learning and problem-solving capabilities have also become the focus of international attention [8]. Physical education (PE), as a course focusing on skill practice and physical fitness training, has been viewed as a secondary and marginal course when compared with other academic subject courses. Most people's impression of PE courses is that they are skill-oriented, emphasizing the learning content while neglecting opportunities for active learning. Therefore, if PE merely involves one-way skill teaching without incorporating students' enthusiasm for sports and peer interaction, these courses will be boring and monotonous, causing students to lose their motivation to continue to exercise. University PE courses are the final influence on individual exercise habits, and have their own meaning and goals, as well as precise value for students' PE and lifelong exercise habits, affecting their sports involvement after they leave school [4]. Therefore, experiences in PE can influence lifelong participation in sport [3]. Cronin et al. [9] discovered that students can develop skills such as teamwork, goal setting, time management, emotional skills, interpersonal communication, social skills, leadership, problem solving, and decision-making through PE. In addition, workplace environments are mostly team-based, and university professors are responsible for training students in the concept of cooperative learning to prepare them for their future jobs [10]. Teachers should demonstrate professional capability in curriculum design and fully utilize various teaching resources and strategies to cultivate students' sports-related knowledge and habits, while creating a more active learning environment. University PE plays a crucial role because it is the final opportunity in the course of students' lifelong learning for them to receive knowledge on the systematic planning of regular exercise and establish a lifelong regular exercise habit.

\subsection{Learning Motivation of PE}

Sport is an essential and important feature of society, becoming a phenomenon closely linked to social, cultural, and educational elements [11]. Motivation means that students have the incentive to pursue the goals they value [12,13], and learning motivation is the motivation to start learning activities, continue them, overcome learning obstacles, and adapt learning styles in specific situations. In other words, it motivates individuals to invest effort, maintain learning, and achieve learning objectives through various objective cognitions in learning activities. In university education, the most essential factor affecting student learning provides experience and knowledge over the course of their learning, and more crucially, it triggers the motivation to participate and learn [14]. Individual differences in capabilities and motivation are often regarded as crucial predictors of learning and training effectiveness [15]. Oleson and Hora [16] verified that students' learning methods fully reflect the essence and connotation of what they are taught. When students are strongly motivated, they concentrate on the learning process and obtain positive learning outcomes. Scarpa and Nart [17] reported that whether exercise is a joy for a person is a crucial factor determining whether the person would start or continue to exercise. How to provide an interesting physical education course is the primary task of a physical education teacher because students' learning effectiveness in physical education courses influences their subsequent involvement in exercise. Chen and Chou [18] indicated that when students lose their learning motivation, schools and educators must apply a new teaching strategy to effectively establish it. In other words, motivation is not merely the driving force behind learning; it also supports the achievement of learning goals. Enhancing students' interest and willingness to learn and facilitating their active participation in the curriculum during learning activities are necessary and urgent topics. In terms of learning motivation, peer interactions in PE activities mostly provide opportunities for success that motivate students in PE tournaments. However, generating strong motivation in active students is crucial, and improvement in the learning process can stimulate students' learning participation while maintaining satisfactory learning performance. 


\subsection{Team-Game Tournaments}

Since the 1970s, numerous scholars have developed education modes for cooperative learning, among them team-game tournaments (TGTs). TGTs enable students to learn in heterogeneous groups sorted according to gender and learning achievements. Their central concepts include positive interdependence, individual accountability, social skills, face-to-face interaction, group processing, and equal opportunities [19], meaning that each individual in the group should make their own contributions and strive to succeed. Cooperative learning mainly emphasizes the formation of small groups of learners with differing capabilities and backgrounds, who pursue the highest standard of individual and group performance through communication, teamwork, and mutual trust [20].

Keegan [21] believed that action research is a useful method of teaching reform because it can be tailored to the needs of teachers and students, and should be considered a basic skill in teachers' lifelong learning. Collaboration with diverse team members is an important competency in society [22]. The main principles of student-centered learning consist of understanding the teaching materials, active learning of students, placement of increased responsibility on students, increased teacher responsibility in creating and promoting an adequate learning environment, and integration of student performance evaluation and feedback provisions [23]. Cooperative learning is a diverse learning mode, with numerous scholars believing that it enhances various skills such as learning motivation [24], motor skills [25], learning outcomes [26], learning attitude and critical thinking capability [27], social skills [28], creativity [29], and problem-solving skills [30]. In addition, Nadrah, Tolla, Ali, and Muris [31] believed that TGTs are the most memorable learning method for students because they can demonstrate their capabilities to the greatest extent possible and work hard to succeed in the team tournament; thus, its cooperative learning model is the optimal solution for improving students' motivation and learning outcomes in PE courses. These studies have all noted that the context of cooperative learning emphasizes students' learning of communication, interaction, encouragement, and motivation, while establishing harmonious interaction models based on social skills during the teamwork process to achieve the desired learning effects. Sevim [32] similarly stressed that the cooperative learning approach enables students to participate in team learning activities and transfer what they have learned to their peers. The far-reaching impact of PE not only provides opportunities for crucial skill learning but also enhances the teamwork that schools value [33]. According to the preceding literature, positive PE experiences or feelings can stimulate students' diverse development. In the context of classroom teaching, teachers are expected to effectively attend to the distinct traits and needs of each student, enabling each of them to achieve success in their teams.

To sum up, we know the importance of physical education courses in university and that they cannot be replaced by other courses. This study attempts to allow students to try to learn through practice and accumulate experiences. The most important thing is to let students compare the traditional system with the intervention of the ability system of the TGT method to understand whether team competition can promote students' learning, motivation, and skills. Therefore, aside from helping students to acquire knowledge and value through different teaching strategies, curriculum design must also help students to continuously develop their capabilities as preparations for the future.

\subsection{Research Purpose and Hypothesis}

The present study has two objectives: the first is to analyze the impact of a TGT unit on learning motivation and motor skills, and the second is to compare learning motivation and motor skill development gained via a traditional teaching method and a TGT unit. Based on the aforementioned influencing factors and literature review, this study proposed that the TGT could enhance the nurturing of student learning motivation and motor skills. Therefore, we propose two research hypotheses, as follows.

Hypothesis 1. Students' learning motivation and motor skills are significantly improved under the TGT. 
Hypothesis 2. TGT students' learning motivation and motor skills are significantly better than those developed via the traditional teaching method.

\section{Method}

\subsection{Research Participants}

In this study, 108 students who enrolled in an advanced basketball course from two classes in a Taiwanese university were recruited as participants. The selection criteria were students enrolled in an elective basketball course and who were above the age of 20. The exclusion criteria were students who were admitted as outstanding student athletes and under the age of 20. The flowchart of the study's sampling process is shown in Figure 1.

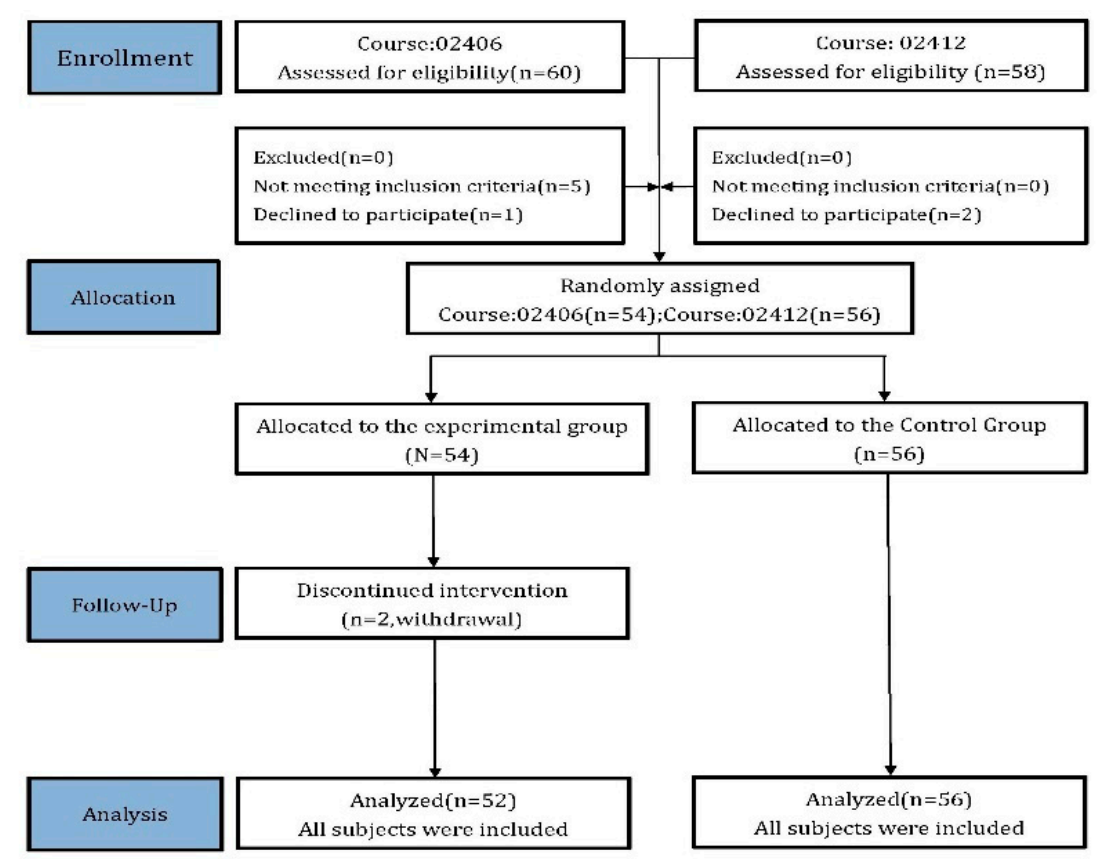

Figure 1. Flowchart of the study's sampling process.

Experimental teaching was implemented based on the class patterns, during which the students were divided into experimental and control groups. The control group, consisting of 56 students (46 male and 10 female, with an average age of $21.19 \pm 0.68$ years), received conventional PE. In the TGT experimental group, constituting 52 students ( 40 male and 12 female, with an average age of $21.98 \pm 0.58$ years), the TGT learning program was implemented, and detailed descriptive data are summarized in Table 1. The participants completed an informed consent that was reviewed and approved by the university's Institutional Review Board (IRB: NRTC-1903) prior to the experiment.

Table 1. Demographic characteristics of the participants.

\begin{tabular}{cccc}
\hline Variable & $\begin{array}{c}\text { Experimental Group } \\
(\boldsymbol{n}=\mathbf{5 2})\end{array}$ & $\begin{array}{c}\text { Control Group } \\
(\boldsymbol{n}=\mathbf{5 6})\end{array}$ & $\begin{array}{c}\text { Total } \\
(\boldsymbol{n}=\mathbf{1 0 8})\end{array}$ \\
\hline Gender (male; female) & $40: 12$ & $46: 10$ & $86: 22$ \\
Age (years; $M[S D])$ & $21.98(0.58)$ & $21.19(0.68)$ & $22.09(0.64)$ \\
Height $(\mathrm{cm} ; M[S D])$ & $170.98(8.81)$ & $168.72(8.01)$ & $169.84(8.45)$ \\
Weight $(\mathrm{kg} ; M[S D])$ & $62.91(13.41)$ & $65.19(15.46)$ & $64.06(14.46)$ \\
BMI $\left(\mathrm{kg} / \mathrm{m}^{2} ; M[S D]\right)$ & $21.41(3.59)$ & $22.73(4.21)$ & $22.07(3.96)$ \\
\hline
\end{tabular}




\subsection{Instruments}

\subsubsection{Learning Motivation Scale for PE}

The learning motivation scale for PE was based on the self-determination theory by Deci and Ryan [34] that promotes concepts of amotivation. It states that the lowest motivation in self-determination is that an amotivational individual only participates in anything passively. It is a macro-level theory that concerns flexible human motivation and personality and facilitates understanding of human cognition, behavior, and emotion under general and specific scenarios. This theory posits that autonomous motivation, autonomous learning, and participation are the three basic psychological needs of students [35]. It emphasizes that a person's motivation includes intrinsic motivation, extrinsic motivation, and amotivation; the degree changes with the self-determination degree, and these changes will affect the individual's participation in an activity. In accordance with the self-determination theory [36], even in the absence of external rewards, one will still choose to take physical education courses and be satisfied and feel happy in the classes, and thus promote the autonomous behavior towards the next step, which also enhances one's intrinsic motivation. In PE, creating a motivational learning environment is important to facilitate engagement and learning, which is also the benign behavior cycle pointed out by other research [37]. Among empirical research studies in PE, some indicate that a self-determination supportive environment and self-determination motivation are positively related [38]. Standage, Duda, and Ntoumanis [39] believe that high self-determination motivation can effectively promote the intention of individuals' participation in exercise, as well as their willingness to study PE courses [40]. Therefore, the scale developed by Luo, Lin, Lee, and Huang [41], and Kao [42], was used as the research instrument in this study, with a total of 25 questionnaire items. The initial scale is examined and reviewed by PE experts and teachers regarding its content and connectivity between framework and constructs. Two hundred and fifty students from Ming Chuan University participated in the pre-test after the content validity was finished, while 231 questionnaires were collected to examine its construct validity by content analysis and factor analysis. The critical value was between 7.17 and 13.68 based on the results from content analysis. Principal axis factors were adapted later for confirmatory factor analysis, extracting three factors (enjoyment, involvement, and competence) in total, with KMO (Kaiser-Meyer-Olkin) of 0.83 and Bartlett's Sphericity Test showing significance $(p<0.001)$. The results indicate the absolute value of "enjoyment" loading was between 0.50 and 0.79 , "competence" loading was between 0.55 and 0.72 , and "involvement" loading was between 0.61 and 0.83 , respectively. The correlation coefficient of each factor was between 0.50 and 0.83 , indicating they are moderately correlated. Cronbach's $\alpha$ is $0.88,0.81$, and 0.87 regarding the reliability of each, while the whole scale shows an extremely high reliability with a 0.91 Cronbach's $\alpha$.

\subsubsection{Basketball Skills Test}

A basketball skills test was chosen and applied based on American Alliance for Health, Physical Education, Recreation \& Dance (AAHPERD) AAHPERD's basketball shooting designed in 1984 [43]. It concentrates on basketball shooting skills from all directions that match the teaching object in this research as well as the participants' shooting levels. The age of targeted participants was between 10 and 22. With validity from 0.65 to 0.95 , its internal consistency reliability $\alpha$ was between 0.54 and 0.95 . Participants with higher scores had higher skills of basketball shooting. The test was conducted in the following steps: (a) Each shooting test was about one minute. Participants had three shots; the first one was counted as practice and the next two shots were added to their score. (b) Participants were told they should shoot at least once from the five dots marked, then get the ball back and dribble to the next dot. (c) Each field goal was counted as five points, two points were made when the shot touched the hoop or backboard, and otherwise, it was zero point. (d) When a participant reached the dots, one foot had to stay behind the line before shooting. No point was recorded if the above rule was violated. 


\subsection{Research Design}

A quasi-experimental design was adopted, wherein the experimental and control groups were subjected to a pre-test and post-test assessment. A week before the experimental intervention, both groups were subjected to a basketball skill pre-test, after which they were divided into three groups of high, medium, and low capabilities based on the critical values of $33 \%$ and $66 \%$ from their pre-test scores. A 12-week teaching session was conducted once a week for $100 \mathrm{~min}$ per session. TGT was used as the basic teaching framework for students in the experimental group, wherein heterogeneous grouping was adopted. After the experiment was completed, the two groups were subjected to a post-test assessment involving the learning motivation scale for PE and a basketball skills test.

\subsection{Course Design}

The team-game tournaments (TGTs) method used in this experiment was based on the teaching methods proposed by DeVries and Slavin [44] to promote learning, which includes: class lectures, group learning, game competition, ability system, and group recognition. The learning content was designed and arranged by the experiment conducting team based on the university's course description and weekly schedule. The course content included violations and fouls, passing and catching balls, shooting balls, offense and defense, etc. In order to ensure the rigor of the research process, the teachers of the two groups of students were the same person on the research team. Before the teaching intervention was introduced, teachers of the research team held two meetings on TGT to confirm the teaching methods and implementation steps, and conducted two weeks of teaching exercises in other classes. The TGT group adopted heterogeneous grouping while the direct teaching group adopted random grouping. In the TGT group, students' achievement types were to be adjusted based on their better or worse performances in competition; only the adjustments were made in the same group.

\subsection{Data Analysis}

Group and time were used as the independent variables in a two-way mixed design. To ensure that any potential confounds were homogenous for the two groups, t-testing or $\mathrm{x} 2$-testing were used to analyze independent samples for continuous or discrete scales of demographic data, respectively. Next, the effects of teaching methods on learning outcomes were analyzed by using the learning motivation in physical education scale and basketball shooting skills test to conduct another mixed ANOVA (Analysis of variance) using a 2 (group: experimental vs. control) x2 (time: pre-test vs. post-test) variable approach. For the ANOVAs, tests of simple main effects were used to follow up on any significant interaction effects that were identified, whereas multiple comparisons were used to follow up on any significant main effects. To control for experiment-wise inflation of $\alpha$, additional Bonferroni adjustments were made. The results for all the analyses satisfied Levene's test of homogeneity.

A small-to-moderate effect size (ES) was calculated according to Cohen's d (0.2 = small effect size; $0.5=$ moderate effect size) which is equal to the mean difference of the groups divided by the pooled standard deviation, and a partial eta-square ( $\eta 2$ ) for the significant main effects and interactions was reported. All statistical analyses were conducted in SPSS 19.0, with $\alpha$ equal to 0.05 .

\section{Results}

\subsection{Homogeneity Test}

As shown in Table 2, the homogeneity of the within-class regression coefficient of the motivation of the PE course and motor skills (respectively $\mathrm{F}=0.102, p=0.750, \eta^{2}=0.439 ; \mathrm{F}=0.952 ; p=0.331$, $\eta^{2}=0.203$ ) were consistent with the hypothesis of the homogeneity of the within-class regression coefficient in the covariance analysis. The data acquired had high homogeneity and were ideal for the experimental intervention. 
Table 2. Summary of a regression coefficient homogeneity test.

\begin{tabular}{cccccccc}
\hline Variables & Variation Sources & $\begin{array}{c}\text { Type III } \\
\text { Sum of Squares }\end{array}$ & df & $\begin{array}{c}\text { Mean } \\
\text { Square }\end{array}$ & F & Sig. & $\eta^{2}$ \\
\hline $\begin{array}{c}\text { Learning } \\
\text { motivation of } \\
\text { the PE course }\end{array}$ & $\begin{array}{c}\text { Regression coefficient } \\
\text { homogeneity } \\
\text { Error }\end{array}$ & 0.001 & 1 & 0.001 & 0.102 & 0.750 & 0.439 \\
\hline Motor skills & $\begin{array}{c}\text { Regression coefficient } \\
\text { homogeneity } \\
\text { Error }\end{array}$ & 1.283 & 104 & 0.012 & & & \\
\hline
\end{tabular}

3.2. Differences in the Motivation of the PE Course among Students with Distinct Competency Levels under Differing Teaching Strategies

Regarding the motivation of the PE course detailed in Table 3, experimental-group students with high, medium, and low competency levels scored 3.44, 3.40, and 3.52, respectively, with an overall score of 3.45. The scores for control-group students with high, medium, and low competency levels were 3.42, 3.27, and 3.36, respectively, with an overall score of 3.35. In terms of motor skill performance, experimental-group students with high, medium, and low competency levels scored 88.41, 78.96, and 66.22, respectively, with an overall score of 78.83. The scores for control-group students with high, medium, and low competency levels were $87.47,78.67$, and 64.32 , respectively, and their overall score was 76.79 .

Table 3. Descriptive statistics for the motivation of learning among students with distinct competency levels under differing teaching strategies.

\begin{tabular}{ccccccc}
\hline \multirow{2}{*}{ Teaching Method } & \multirow{2}{*}{$\begin{array}{c}\text { Competency } \\
\text { Level }\end{array}$} & \multicolumn{2}{c}{ Learning Motivation } & \multicolumn{2}{c}{ Motor Skills } & \multirow{2}{*}{ Numbers } \\
\cline { 3 - 6 } & & Pre-Test (SD) & Post-Test (SD) & Pre-Test (SD) & Post-Test (SD) & \\
\hline \multirow{2}{*}{ TGT } & High & $3.35(0.21)$ & $3.44(0.22)$ & $87.41(3.95)$ & $88.41(3.67)$ & 17 \\
(experimental & Medium & $3.32(0.32)$ & $3.40(0.31)$ & $78.24(3.63)$ & $78.96(2.93)$ & 17 \\
group) & Low & $3.36(0.22)$ & $3.52(0.23)$ & $64.78(4.37)$ & $66.22(7.15)$ & 18 \\
& Sum & $3.34(0.25)$ & $3.45(0.25)$ & $76.58(10.22)$ & $77.83(9.82)$ & 52 \\
\hline \multirow{2}{*}{ Conventional } & High & $3.38(0.24)$ & $3.42(0.21)$ & $86.32(3.36)$ & $87.47(3.82)$ & 19 \\
teaching & Medium & $3.31(0.28)$ & $3.27(0.27)$ & $75.33(4.72)$ & $78.67(5.36)$ & 18 \\
(control group) & Low & $3.33(0.21)$ & $3.36(0.20)$ & $63.79(4.99)$ & $64.32(5.12)$ & 19 \\
& Sum & $3.34(0.24)$ & $3.35(0.23)$ & $75.15(10.70)$ & $76.79(10.79)$ & 56 \\
\hline
\end{tabular}

Regarding the motivation of the PE course in Table 4, the interaction between Factors A (teaching strategy) and B (competency level) was non-significant $\left(\mathrm{F}=0.88, p=0.42, \eta^{2}=0.107\right)$, thus verifying the main effect. Factor A (teaching strategy) achieved a significant difference $\left(F=4.71, p=0.03, \eta^{2}=0.24\right)$ and was directly compared with its marginal average. Factor B (competency level) did not achieve a significant difference $\left(F=1.77, p=0.17, \eta^{2}=0.13\right)$. The interaction between teaching strategy and competency level was non-significant, although Factor A (teaching strategy) achieved a significant difference individually. The marginal average showed that TGT $(M=3.45)$ was significantly superior to conventional teaching methods $(\mathrm{M}=3.35)$ in terms of students' motivation of learning.

The interaction between Factors A (teaching strategy) and B (competency level) for motor skills was non-significant $\left(\mathrm{F}=0.85, p=0.43, \eta^{2}=0.02\right)$, thus verifying the main effect. Factor A (teaching strategy) did not achieve a significant difference $\left(F=7.29, p=0.06, \eta^{2}=0.06\right)$, whereas Factor $B$ (competency level) reached a significant difference $\left(F=182.85, p=0.00, \eta^{2}=0.28\right)$. The interaction between teaching strategy and competency level was insignificant, although Factor B (competency level) achieved a significant difference, with the marginal average indicating that the motor skills of high- $(M=87.94)$ and medium-achieving students $(M=78.82)$ were significantly superior to those of the low-achieving students $(M=65.14)$ under conventional teaching. 
Table 4. Between-subjects effects.

\begin{tabular}{|c|c|c|c|c|c|c|c|}
\hline Variable & Sources & Type III Sum of Squares & df & Sum of Mean Squares & $\mathbf{F}$ & $\mathbf{P}$ & $\eta^{2}$ \\
\hline \multirow{5}{*}{$\begin{array}{l}\text { Learning } \\
\text { motivation } \\
\text { of the PE } \\
\text { course }\end{array}$} & Teaching strategy(A) & 0.28 & 1 & 0.285 & 4.71 * & 0.03 & 0.24 \\
\hline & Competency level(B) & 0.21 & 2 & 0.107 & 1.77 & 0.17 & 0.13 \\
\hline & $A * B$ interaction & 0.10 & 2 & 0.052 & 0.88 & 0.42 & 0.10 \\
\hline & Error & 6.16 & 102 & 0.060 & & & \\
\hline & Sum & 1259.06 & 108 & & & & \\
\hline \multirow{5}{*}{$\begin{array}{l}\text { Motor } \\
\text { skills }\end{array}$} & Teaching strategy (A) & 175.13 & 1 & 175.13 & 7.29 & 0.06 & 0.06 \\
\hline & Competency level (B) & 8785.43 & 2 & 4392.71 & 182.85 * & 0.00 & 0.28 \\
\hline & $\mathrm{A} * \mathrm{~B}$ interaction & 40.88 & 2 & 20.44 & 0.85 & 0.43 & 0.02 \\
\hline & Error & 2450.30 & 102 & 24.02 & & & \\
\hline & Sum & $667,314.00$ & 108 & & & & \\
\hline
\end{tabular}

Notes: * $p<0.05$.

\section{Discussion}

\subsection{Impact of TGT on PE Learning Motivation}

After the 12-week TGT experimental course, no significant differences were found between different teaching strategies applied to students of different competency level. Independent verification of the main effects revealed a significant difference between the two teaching strategies, with TGT being superior to the conventional teaching method in terms of students' motivation of learning. This study argued that TGT can help students improve their learning motivation for PE. After the experimental process, students understood that personal skills were not equal to team tournament performance, and low-achieving students could gain a sense of accomplishment in the TGT model, with each student having the opportunity to succeed in the tournament, thereby enhancing their learning motivation. This supports the conclusions of Tombak and Altun [45], and Johnson et al. [25], who have noted that cooperative learning has a positive impact on students' motivation, demonstrating that the teaching of this learning style enhances students' learning effectiveness and motivation in PE. The TGT spirit is that the success of the team depends on the success of individual members, whose learning is enhanced through the establishment of a tournament for mutual competition and growth, enabling students to demonstrate their concentration and active participation [46]. As stated by Wodarski and Feit [47], and Chen and Chen [48], TGT provides students with the opportunity to interact with their peers while learning, and the improvement of the incentive mechanism has a positive impact on the motivation of continuous improvement and students' learning process. If viewed according to the motivation theory model by Pintrich [49], individuals who are oriented toward goals and have higher expectations for success are more likely to be engaged in their work and persist rather than give up when they encounter difficulties. Students can receive more support in the TGT learning process than in individual learning, generating a sense of participation and identity. TGT not only provides opportunities for students to learn to succeed through the mutual sharing of knowledge and skills in a process that achieves knowledge integration, but also promotes more social and collaborative behaviors.

In general, TGT transforms students' learning approach into active social interaction and peer support, enhancing their willingness to learn while maintaining their interest and learning endeavors. In this study, the TGT pedagogical method of actively using group rewards and individual performance responsibility was more capable of enhancing students' learning motivation, because more interaction and mutual motivation were provided to achieve optimal competition results; thus, TGT was the main mechanism facilitating students' learning motivation. In the experimental group, the tournament structure enabled peers to develop positive goals and share knowledge, with students appreciating the importance of their own and others' success in learning. The students in this group therefore knew who required support, assistance, and encouragement. In addition, rewards and commendation in the teaching process can be regarded as a means of enhancing motivation. Within the TGT structure, each individual has the same chance to succeed, and all members are rewarded when the group achieves a goal. Therefore, motivation was expanded due to mutual encouragement in the TGT teams, 
and some students with weak learning motivation changed their original attitude to active collaboration and participation, because they sensed the group members' obvious expectations. The TGT learning environment helps teachers improve students' motivation because students have the opportunity to socialize, make decisions, and receive peer attention.

\subsection{Impact of TGT on Motor Skills}

After the 12-week TGT course intervention, the interaction between teaching strategy and competency level did not achieve a significant difference. Independent verification of the main effects revealed that competency level resulted in a significant difference in motor skill performance, although the skill scores of the experimental group were not significantly different from those of the control group after the experimental intervention. This study demonstrates that TGT intervention cannot effectively improve motor skills, which supports the argument of Miller et al. [44] that striking a balance between educational games and motor skills is difficult. Once the game begins, the process may reduce the focus on developing motor skills and inhibit the development of perception and skills. Hsu, Li, and Pan [50] also suggested that teachers should frequently adopt PE models when arranging team tournaments to cultivate students' morale and motivation to participate, and that PE students should pay more attention to and encourage students with unsatisfactory performance. However, unlike Nadrah et al. [31], they discovered that students who adopted a TGT model in PE courses achieved higher grades than those who used the conventional learning approach. Huang et al. [51] also reached a different result, indicating that cooperative learning is effective because the strategy of blended team discussion contributes to skill performance in basketball activities, providing the appropriate challenge for the organizations to achieve their team objectives in sports environments. From the perspective of motor skills learning, Singer [52] noted that it involves cognition being formed as the basis of motor execution. In other words, the cognition of the game process is the first stage for motor skill learning, and learners must understand their desired motor skills if they are to master them. Although motor skill learning enhanced the motivation of low-achieving students in TGT teaching and increased their participation, proficiency in these skills still requires a series of repetitive practices to reach the mastery stage. Differences are inferred to exist between age groups or curriculum designs, and although TGT emphasizes the stimulation of students' motivation through games, it neglects the mastery of skills.

\section{Conclusions and Recommendations}

After the TGT experimental course intervention was employed, it was discovered to be superior to conventional teaching methods in terms of students' learning motivation in the PE course. Diverse and effective learning methods can be provided through the TGT context, increasing students' active learning and enhancing their learning interest, resulting in a positive development in their learning attitude. In addition, students have the opportunity to act according to the interests and individual roles that best suit them, thereby facilitating their success. The core value of TGT focuses on the learning process and learners' cooperative capabilities, enabling low-achieving students to gradually participate from the margins of the class until they become active learners. Therefore, the intervention and probing of effective teaching strategies is the key factor for maintaining curriculum development and strong learning motivation [53]. The decisive impact of games on the development of human cognition and social emotion can be realized through game-based learning [54]. Innovative curriculum design and teaching method development may improve students' motivation and solve the problems in their learning process. In terms of motivation development, peer interactions during PE mostly provide students with an opportunity to produce motivation in tournaments during PE classes. During cooperative learning, the arrangement of learning activities and the environment differ from conventional PE and are helpful to students. Through mutual learning and the reward model, students can improve their learning effectiveness and interactivity, enhancing their learning interest while making learning more rewarding through the sharing of experiences. 
Based on the results of this study, the following recommendations are proposed to serve as a reference for both teaching applications and future relevant studies. Despite the TGT model effectively enhancing learning motivation, teachers are still responsible for disseminating the correct rules, knowledge, and skills to students, and making use of discussion within teams to raise more ideas from distinct voices; they should also pay attention to whether students' have sufficient time to practice their skills. Because this study conducted analysis from the quantitative perspective of basketball courses, whether it is appropriate to apply the TGT model to individual sports remains unknown and is worthy of in-depth discussion. Furthermore, this study only conducted research on students from one university in Taiwan. However, whether any differences are present in the results of students from distinct regions and socioeconomic backgrounds remains to be investigated.

Author Contributions: Conceptualization, Y.-J.L., M.-L.L., C.-H.H., C.-C.L., and C.-C.K.; data curation, C.-H.H., C.-C.L., and C.-C.K.; formal analysis, Y.-J.L., M.-L.L., C.-H.H., C.-C.L., and C.-C.K.; funding acquisition, Y.-J.L.; investigation, M.-L.L., C.-H.H., and C.-C.K.; methodology, Y.-J.L., M.-L.L., C.-H.H., C.-C.L., and C.-C.K.; project administration, Y.-J.L., M.-L.L., and C.-C.K.; resources, M.-L.L., and C.-C.L.; software, C.-H.H., and C.-C.L.; visualization, C.-H.H., and C.-C.K.; writing—original draft, Y.-J.L., M.-L.L., C.-H.H, and C.-C.K.; writing-review and editing, Y.-J.L., and C.-C.K. All authors have read and agreed to the published version of the manuscript.

Funding: This research received no specific grant from any funding agency in the public, commercial, or not-for-profit sectors.

Acknowledgments: The corresponding author wants to thank Ming Chuan University (MCU, Taiwan) for supplying the necessary material for the execution of the work; and acknowledges all teachers and students who participated in this study.

Conflicts of Interest: The author(s) declare no potential conflicts of interest with respect to the research, authorship, and/or publication of this article.

\section{References}

1. Moreno, J.A.; González-Cutre, D.; Martín-Albo, J.; Cervelló, E. Motivation and performance in physical education: An experimental test. J. Sports Sci. Med. 2010, 9, 79-85.

2. Kao, C.-C.; Luo, Y.-J. Effects of multimedia-assisted learning on learning behaviors and student knowledge in physical education lessons: Using basketball game recording as an example. Int. J. Emerg. Technol. Learn. 2020, 15, 119-139. [CrossRef]

3. Alcalá, D.H.; Garijo, A.H. Teaching games for understanding: A comprehensive approach to promote student's motivation in physical education. J. Hum. Kinet. 2017, 59, 17-27. [CrossRef]

4. Huang, W.Y. Laws/regulations and compulsory/elective course systems for physical education curriculum of university. Sport Res. Rev. 2017, 140, 19-26.

5. Luo, Y.-J. The influence of problem-based learning on learning effectiveness in students' of varying learning abilities within physical education. Innov. Educ. Teach. Int. 2019, 56, 3-13. [CrossRef]

6. Capar, G.; Tarim, K. Efficacy of the cooperative learning method on mathematics achievement and attitude: A meta-analysis research. Educ. Sci. Theory Pr. 2015, 15, 553-559.

7. Taiwan PISA National Center. The Programme for International Student Assessment. Available online: http://pisa.nutn.edu.tw/pisa_tw_03.htm (accessed on 14 May 2019).

8. Chien, F.M.; Lee, Y.M.; Wu, H.L.; Jen, C.I. Instructional design of team-game-tournament and Google Earth integrated into differences in regional lives of social studies in the elementary school. J. Reg. Soc. Dev. Res. 2016, 7, 29-59.

9. Cronin, L.D.; Allen, J.; Mulvenna, C.; Russell, P. An investigation of the relationships between the teaching climate, students' perceived life skills development and well-being within physical education. Phys. Educ. Sport Pedagog. 2018, 23, 181-196. [CrossRef]

10. Govender, C.M.; Wait, M. Work integrated learning benefits for student career prospects-Mixed mode analysis. S. Afr. J. High. Educ. 2017, 31, 49-64. [CrossRef]

11. Mackintosh, C.; Liddle, J. Emerging school sport development policy, practice and governance in England: Big Society, autonomy and decentralisation. Education 2015, 43, 603-620. [CrossRef]

12. Moussa, M. Variances in student motivation and educators' and school leaders' tactics to motivate: An integrative literature. Silpakorn Univ. J. Soc. Sci. Humanit. Arts 2015, 15, 59-86. 
13. Reynolds, T.M.; Cain, B.; Manarino-Leggett, P. Paving the way: The journey towards culturally responsive teaching for teacher educators and teachers. Gstf J. Educ. 2014, 2, 4.

14. Tella, A. The impact of motivation on student's academic achievement and learning outcomes in mathematics among secondary school students in Nigeria. Eurasia. J. Math. Sci. Tech. Ed. 2007, 3, 149-156.

15. Cole, M.S.; Feild, H.S.; Harris, S.G. Student learning motivation and psychological hardiness: Interactive effects on students' reactions to a management class. Acad. Manag. Learn. Educ. 2004, 3, 64-85. [CrossRef]

16. Oleson, A.; Hora, M.T. Teaching the way they were taught? Revisiting the sources of teaching knowledge and the role of prior experience in shaping faculty teaching practices. High. Educ. 2014, 68, 29-45. [CrossRef]

17. Scarpa, S.; Nart, A. Influences of perceived sport competence on physical activity enjoyment in early adolescents. Soc. Behav. Personal. Int. J. 2012, 40, 203-204. [CrossRef]

18. Chen, C.H.; Chou, M.H. Enhancing middle school students' scientific learning and motivation through agent-based learning. J. Comput. Assist. Learn. 2015, 31, 481-492. [CrossRef]

19. Johnson, D.; Johnson, R. Learning Together and Alone: Cooperative, Competitive, and Individualistic Learning, 4th ed.; Allyn \& Bacon: Boston, MA, USA, 1994.

20. Dyson, B. The implementation of cooperative learning in an elementary physical education program. J. Teach. Phys. Educ. 2002, 22, 69-85. [CrossRef]

21. Keegan, R. Action research as an agent for enhancing teaching and learning in physical education: A physical education teacher's perspective. Phys. Educ. 2016, 73, 255-284.

22. Lee, H.-J.; Kim, H.; Byun, H. Are high achievers successful in collaborative learning? An explorative study of college students' learning approaches in team project-based learning. Innov. Educ. Teach. Int. 2017, 54, 418-427. [CrossRef]

23. Wang, L.; Myers, D.L.; Yanes, M.J. Creating student-centered learning experience through the assistance of high-end technology in physical education: A case study. J. Instr. Psychol. 2010, 37, 352-356.

24. Ning, H.; Hornby, G. The impact of cooperative learning on tertiary EFL learners' motivation. Educ. Rev. 2014, 66, 108-124. [CrossRef]

25. Johnson, D.W.; Johnson, R.T.; Stanne, M.B. Cooperative Learning Method: A Meta-Analysis; Cooperative Learning Center, University of Minnesota: Minneapolis, MN, USA, 2000; Available online: https://pdfs. semanticscholar.org/93e9/97fd0e883cf7cceb3b1b612096c27aa40f90.pdf (accessed on 11 May 2019).

26. Adu, E.O.; Galloway, G. Information and communication technologies (ICT) and teacher education preparation in South Africa: Implications for 21st century classroom-based practice. J. Commun. 2015, 6, 242-247. [CrossRef]

27. Lin, Y.P.; Lin, T.Y.; Wang, W.Y. The effect of using tactic game tournament of cooperative learning in PE with different learning styles students in critical thinking and learning attitude. J. Taiwan Sport Pedagog. 2013, 8, 15-30.

28. Arisoy, B.; Tarim, K. The effects of cooperative learning on students' academic achievement, retention and social skill levels. Univ. J. Educ. 2013, 28, 1-14.

29. Gossett, M.; Fischer, O. Bringing together critical thinking and cooperative learning between two schools. Strategies 2005, 19, 27-30. [CrossRef]

30. Gorucu, A. The investigation of the effects of physical education lessons planned in accordance with cooperative learning approach on secondary school students problem solving skills. Educ. Res. Rev. 2016, 11, 998-1007.

31. Nadrah, N.; Tolla, I.; Ali, M.S.; Muris, M. The effect of cooperative learning model of teams games tournament (TGT) and students' motivation toward physics learning outcome. Int. Educ. Stud. 2017, 10, 123-130. [CrossRef]

32. Sevim, O. Influence of the subject jigsaw technique on elementary school seventh grade students' academic achievement and on their problem solving skills. Educ. Sci. 2015, 40, 385-400. [CrossRef]

33. Hoffman, E.M. Faculty and student relationships: Context matters. Coll. Teach. 2014, 62, 13-19. [CrossRef]

34. Deci, E.L.; Ryan, R.M. A motivation approach to self: Integration in personality. In Nebraska Symposium on Motivation. Perspectives on Motivation; Dienstbier, R., Ed.; University of Nebraska Press: Lincoln, NE, USA, 1991; pp. 237-288.

35. Bang, M.; Wohn, K.; Shi, C. The establishment of an e-learning system based on SDT. Int. J. Emerg. Technol. Learn. 2014, 9, 43-49. [CrossRef] 
36. Ryan, R.M.; Deci, E.L. Intrinsic and extrinsic motivations: Classic definitions and new directions. Contemp. Educ. Psychol. 2000, 25, 54-67. [CrossRef] [PubMed]

37. Chang, Y.-K.; Chen, S.; Tu, K.-W.; Chi, L.-K. Effect of autonomy support on self-determined motivation in elementary physical education. J. Sports Sci. Med. 2016, 15, 460-466. [PubMed]

38. Hagger, M.S.; Chatzisarantis, N.L.D.; Barkoukis, V.; Wang, C.K.J.; Baranowski, J. Perceived autonomy support in physical education and leisure time physical activity: A cross-cultural evaluation of the trans-contextual model. J. Educ. Psychol. 2005, 97, 376-390. [CrossRef]

39. Standage, M.; Duda, J.L.; Ntoumanis, N. A model of contextual motivation in physical education: Using constructs from self-determination and achievement goal theories to predict physical activity intention. J. Educ. Psychol. 2003, 95, 97-110. [CrossRef]

40. Ntoumanis, N. A prospective study of participation in optional school physical education using a self-determination theory framework. J. Educ. Psychol. 2005, 97, 444-453. [CrossRef]

41. Luo, Y.J.; Lin, M.L.; Lee, M.L.; Huang, C.Y. Development of study experience scale for university students. J. Sport Leis Hosp. Res. 2016, 11, 31-42.

42. Kao, C.C. A study on influences from student team achievement division to basketball strategy cognition and learning motivation. J. Taiwan Sport Pedagog. 2012, 7, 23-40.

43. American Alliance for Health, P.E., Recreation; Dance. Technical Manual: Health Related Physical Fitness; The American Alliance for Health, Physical Education, Recreation and Dance: Reston, VA, USA, 1984.

44. DeVries, D.L.; Slavin, R.E. Teams-Games-Tournament: A final Report on the Research; Center for Creative Leadership: Woluwe-Saint-Lambert, Belgium, 1978.

45. Tombak, B.; Altun, S. The effect of cooperative learning: University example. Eurasian J. Educ. Res. 2016, 64, 173-196. [CrossRef]

46. Gonzalez, A.; Jennings, D.; Manriquez, L. Multi-faceted impact of a team game tournament on the ability of the learners to engage and develop their own critical skill set. Int. J. Eng. Educ. 2014, 30, 1213-1224.

47. Wodarski, J.S.; Feit, M.D. Adolescent preventive health and team-games-tournaments: Five decades of evidence for an empirically based paradigm. Soc. Work Public Health 2011, 26, 482-512. [CrossRef] [PubMed]

48. Chen, K.D.; Chen, P.K. Research on the relation the characteristics of the faculty and the commitment to continuous improvement of motivations and student study processes. Asia Pac. Educ. Rev. 2017, 18, 439-449. [CrossRef]

49. Pintrich, P.R. A motivational science perspective on the role of student motivation in learning and teaching contexts. J. Educ. Psychol. 2003, 95, 667-686. [CrossRef]

50. Hsu, W.T.; Li, H.H.; Pan, Y.H. Student misbehavior in physical education: The role of $2 \times 2$ achievement goals and moral disengagement. J. Sports Sci. Med. 2017, 16, 302-310. [PubMed]

51. Huang, M.Y.; Tu, H.Y.; Wang, W.Y.; Chen, J.F.; Yu, Y.T.; Chou, C.C. Effects of cooperative learning and concept mapping intervention on critical thinking and basketball skills in elementary school. Think. Ski. Creat. 2017, 23, 207-216. [CrossRef]

52. Singer, R.D. Motor Learning and Human Performance; Macmillan: New York, NY, USA, 1980.

53. Mercado, C.A.I.; Bayugo, E.J.S.M.; Leynes, Z.L.S.; Lontok, C.J.B.; Medilla, D.K.M.; Manongsong, J.L. Accounting students' learning satisfaction of professional subjects as basis for continuous improvement. Asia Pac. J. Educ. Arts Sci. 2016, 3, 99-109.

54. Sinelnikov, O.; Hastie, P. A motivational analysis of a season of sport education. Phys. Educ. Sport Pedagog. 2010, 15, 55-69. [CrossRef]

(C) 2020 by the authors. Licensee MDPI, Basel, Switzerland. This article is an open access article distributed under the terms and conditions of the Creative Commons Attribution (CC BY) license (http://creativecommons.org/licenses/by/4.0/). 